\title{
How can Dialogue Journal Writing improve learners' writing performance in the English as a Second Language context?
}

\author{
Maryam Foroutan ${ }^{1}$, Nooreen Noordin ${ }^{2}$, Mohd. Sahandri Gani Hamzah ${ }^{3}$ \\ 1, 2 (Department of Humanities Studies and Language Education, Faculty of Educational Studies, University \\ Putra Malaysia, Malaysia) \\ ${ }_{3}^{3}$ (Sultan Idris Education University, Tanjung Malim, 35900, Perak Darul Ridzuan, Malaysia)
}

\begin{abstract}
This paper compared the effect of two different methods in writing including dialogue journal writing $(D J W)$ and Topic-Based writing (TBW) on the overall writing performance based on categories, content, organization, vocabulary, language use, and mechanics. In this quasi-experimental study, forty intermediate English students at a Malaysian university participated. TBW group $(n=20)$ received conventional writing instruction through which teacher corrected and provided feedback on students' writing tasks explicitly, while DJW group $(n=20)$ applied dialogue journal writing through which the teacher provided feedback indirectly by rewriting the sentences and handing the students some examples compiled in the handouts. The quantitative research findings suggest that each writing method can be applied by writing instructors to assist their learners on different writing tasks. Implications of the study will be discussed based on the findings reported.
\end{abstract}

Keywords: Communicative approach, dialogue journal writing, motivation, topic-based writing, writing performance

\section{INTRODUCTION}

Teaching writing has been one of the most overwhelming challenges that English teachers encounter in their classes. Concentration more on other skills, writing seems lagged behind. Indeed, writing is an art done under particular conditions that necessitates more elaboration and clarity compared to other skills. Applying the most effective methods in writing classes to assist their learners to learn more effectively has been always one of the writing teachers' concerns. However, the scarcity of specific and conclusive theory in introducing an informative process of learning and teaching writing has been reported by writing researchers [e.g. 1].

Primarily, there have been two main approaches in writing classes. From the early $20^{\text {th }}$ century into the 1960s, a model in composition instruction has been brought into language learning known as the "traditional paradigm" or "product approach". According to this approach, L1 speakers have to be acquainted with "reading and analysis of literature" in which they are required to read novels and essays or poetry and analyze them in written compositions. In this approach, students were given formulas and rules to follow based on their teachers' models and the assignments are evaluated by the teachers [2].

The product approach has been widely applied by writing instructors. The topics are all assigned for the students and students are expected to write their essays based on the given topics. It focuses mostly on teachercentered approach where students have no responsibility for their own learning.

"process approaches" were widely used in the 1960s, through which the writers were regarded as "creators of original ideas", while written discourse is seen as a tool for conveying human's thoughts as well as a method for solving problems, uncovering and expressing ideas [2, p.5]. Dialogue journal writing as a type of process approach writing, has been regarded as a written, regular discussion between the teacher and student in which the student writes based on his or her own topic of interest and the teacher comments as a partner in a discussion rather than a grader or evaluator [3]. Using this method, students are not assigned a topic to write about, but they can write about their desired topics and worries. It has been reported that when students write about topics of their interest, they enjoy the process, have lower anxiety and consequently improve their writing quality [4-8].

[8] believes that "rather than overt correction of student errors, correct grammatical forms of structures can be modeled in the course of the interaction" (p.27). Through this interaction teacher provides feedback and comments by writing the correct grammatical forms and structures, while students are expected to model them. This interaction provides communicative context for ESL learning as the purpose of dialogue journal writing is not focusing on forms, but on communication [9].

Regarded as a technique in reflecting learner-centered pedagogy with a socio-cultural notion, dialogue journal writing as identified by [10] offers constant reading and writing interaction. This technique provides opportunity for students to use writing as a communicative method, besides teachers can develop their awareness in their students' concerns and desires. [7] also believes that continuous writing-reading activity in dialogue journal offers learner the opportunity to practice writing and language and this practice results in fluency in writing. 
Dialogue journal through teachers' and students' responses promote the notion of scaffolding [11]. [12] proposes that dialogue journal writing offers a proper context to reflect and activate the learner's zone of proximal development. The idea of scaffolding originated from [13] social cultural theory and the Zone of proximal development in which students' success to the next step in development is through the scaffolding method. Based on the zone of proximal development, students are guided to the higher level until they can perform independently. It is assumed that the child in any development steps will be confronted by many problems where he or she requires some details, clues or encouragement to stay motivated. Considering dialogue journal writing as a perfect reflect of cognitive development theory, [13] identified interaction and conversation as two key principles in understanding and learning.

Several advocates of dialogue journal writing have addressed and supported the effectiveness use of dialogue journal in writing skills. [14] reports the advantages of using dialogue journal in the classroom including: a) providing opportunity for learners to express their ideas and feelings directly to the teacher, b) providing meaningful context for both teachers and learners to use writing as a tool for communication, c) decreasing the "red pen correction" stress which has had negative effect on writing, d) and finally, providing a clear data for teachers to observe their students' improvement in writing. [15] also emphasizes that writing is easier and more manageable for the students when they write about their favorite topics, particularly when they receive real responses from their counterparts which makes their efforts meaningful and worthwhile. In his research, [16] observed that the use of dialogue journal aided students in monitoring and developing their own styles; moreover, students became motivated to write as they were not graded nor directly corrected.

Along with some other advantages in using dialogue journals in students' language learning, some researchers claimed that this technique can benefit students in improving writing skills [5, 10, 3, 17], learning new vocabulary and idiomatic expressions as well as developing their self-confidence [18]. It also helps them in syntactic development [16], language acquisitions, increasing their self-esteem [11], improving their spelling, grammar, capitalization and punctuation [19] and communicative language functions [12]. However, most of these studies are not research-based studies, nor have compared this method with other common methods to identify their differences in their effects on writing performance. As mentioned by [20], even though many researchers have provided evidences and acknowledged the potential advantages of dialogue journal, this tool is not applied extensively in second language learning. Thus, more research-based studies are required to investigate dialogue journals' effectiveness in improving students' writing performance.

\subsection{Research objectives}

The main objective of this study is to determine the effect of dialogue journal writing on ESL students' writing performance

\section{The specific objectives are:}

1. To compare the effect of dialogue journal writing and topic-based writing with regard to students' overall writing performance.

2. To compare the effect of dialogue journal writing and topic-based writing with regard to content.

3 . To compare the effect of dialogue journal writing and topic-based writing with regard to language use.

4. To compare the effect of dialogue journal writing and topic-based writing with regard to vocabulary.

5. To compare the effect of dialogue journal writing and topic-based writing with regard to organization.

6. To compare the effect of dialogue journal writing and topic-based writing with regard to mechanics.

\subsection{Methods in improving writing}

\section{REVIEW OF LITERATURE}

Among the four skills, writing is regarded as one of the most demanding skills; unlike others, necessitates concentration and constant practice. ESL learners have to struggle with vocabulary, language use, style techniques and sentence formation when creating an essay. [21] suggests that "good writing requires clarity and rigor in the thought process" (p. 2), which can only be developed through practice. Logically, without continual practice, the learning process of writing skills will be slow. Writing involves drafting and revising, and thought prior to the final stage [22]. One of the reasons which brings about difficulty in writing relates to its process essentiality which cannot be completed [23]. [24] states that writing well is a skill which is usually learned or culturally acquired as a set of patterns in formal instructional or other settings. Likewise, [25] expresses that having something to share and the talent to put it in words are the outcomes of a great feeling of confidence and accomplishment.

As a matter of fact, students should be personally involved in writing and teachers should be facilitators in this process. Most importantly, teachers should be aware of the skills they are endeavoring to develop. They need to choose the sort of exercises which can facilitate the learning of those specific skills. Once students' needs and means of implementation are determined, teachers should focus on the process which ensures 
students' participation. If these steps are achieved successfully, the teachers can expect both enthusiasm and effective learning [26].

Writing is a process demanding rich and frequent chances for social interaction and practice to reach to the satisfied level [27]. By learning from more expert readers and writers, learners are able to construct their own meanings and expectations. Success will be more observable when students are engaged in a written activity with a purpose; particularly when the topics and themes are in accordance with the learners' interests.

Besides creating enthusiasm among learners, dialogue journal writing is introduced as a method which offers real topics to the learners to make their writing more meaningful. Dialogue journal writing can be used as a tool in collaborative learning as well. Thus, another role of language teachers in writing classes is providing the appropriate environment for this collaborative writing.

\subsection{Motivation in language learning}

One of the most vital concerns in language learning and teaching is student's level of motivation. [28] defines motivation as "an internal state or condition that servers to activate or energize behavior and give it direction" (p. 1). Intrinsic motivation as a type of motivation that pushes organisms and human being to investigate, explore the environment and encourages curiosity in discovering new activities [29], and is defined as "the doing of an activity for its inherent satisfaction rather than for some separable consequence" is being contrasted to the extrinsic motivation which relates to "a construct that pertains whenever an activity is done in order to attain some separable outcome" [30, p.56].

[28] determines two categories of actions (Table 1) which the teachers can consider to enhance the students' intrinsic and extrinsic motivation in their classes.

Table 1. Two categories of activities [28]

\begin{tabular}{|c|c|}
\hline Intrinsic & Extrinsic \\
\hline Explain or show why learning a & Provide clear expectations \\
particular content or skill is important & Give corrective feedback \\
Create and/or maintain curiosity & Provide valuable rewards \\
Provide a variety of activities and & Make rewards available \\
sensory stimulations & \\
Provide games and simulations & \\
Set goals for learning & \\
Relate learning to student needs & \\
Help student develop plan of action & \\
\hline
\end{tabular}

[28] further recommends using intrinsic tactics as soon as teachers recognize their students' low motivation. He highlights that although the extrinsic strategies might be valuable, the important issue to bear in mind is that the student will do that activity as long as he or she is motivated by the teacher. Once the student feels independent from the teacher, he/she will quit and do another activity based on his or her desire.

In ESL writing, students should be motivated intrinsically. According to [24], if learners are motivated in their writing, they will develop a higher level of proficiency and positive attitudes which can affect their writing performance positively. In the role of motivation in a writing task, [31] explain:

In a difficult and complex task like this (writing), motivational issues will assume particularly prominent status. Writers need to develop strong beliefs in the relevance and importance of writing and, as they grapple with writing's complexities and frustrations, learn to be patient, persistent, and flexible. Although we believe that these beliefs and attitudes ultimately fall clearly within the realm of intrinsic motivation, their development is in the hands of those who set the writing tasks and react to what has been written [31, p. 26].

One of the techniques to motivate students in writing is to make writing meaningful [32]. [24] states that if learners perceive writing tasks to be useless, they will not concentrate on their writing, and as the result, the probability of having many mistakes will be higher.

\subsection{Studies in using dialogue journal writing}

A great body of research has been allocated to examine the effects of dialogue journal writing on students' learning. Almost all of these studies have similar results with regard to the effects of dialogue journal in assisting learners to reflect their thoughts and improve their learning. Past literature on dialogue journal writing explicitly claim that it improves writing proficiency especially in fluency and accuracy (4, p.3]. This improvement in accuracy is because of the communicative nature of dialogue journals when the interlocutors 
share interests and information and try to convey their meanings clearly in order to achieve mutual understanding as well as to avoid misunderstanding.

Examining six ESL university students' dialogue journal entries for 15 weeks, [7] found that students felt more comfortable in writing after being exposed to dialogue journal writing. The subjects in the study improved their fluency in writing while fewer errors were observed in their texts. The researchers also found out that the students could express their thoughts better in English.

In another study, [5] identified the effects of dialogue journal writing in an experimental study conducted for ten weeks. Students' writing quality, writing apprehension and reading comprehension were the variables investigated in this study, where the experimental group using dialogue journals were compared with the control group which did not keep journals. The results of the study showed that the writing quality in the experimental group increased higher than their counterparts, whereas there was no significant difference in reading improvement and writing apprehension between these groups.

[18] also remarked some of the benefits in using dialogue journal in his study. In this study, forty two ESL high school freshmen were asked to keep dialogue journals with their instructor for 6 months and then a survey was conducted to discover students' feelings in learning, what they enjoyed and learned in reading and writing, their feelings about the questions the researcher had asked them and their interest to continue writing in the journals. Results from the survey revealed that some students learned new vocabulary and how to create sentences. Some explained their improvement in linguistic and cultural elements. Others stated they learned idiomatic expressions. For example a student commented that "I learned idiom and a way making sentences" (p. 3). Students were more interested in reading when receiving their journals. In addition, students reported that their speaking abilities improved after using dialogue journals and the students effectively communicated through journals and could initiate speaking about their favorite topics, answer the questions and ask the questions successfully and finally this experience resulted in their greater confidence to communicate.

In another study by [33], sixteen students were randomly selected and from each student 6 journals: two from the beginning of the first semester, two from the end of the first semester, and two from the end of the third semester were collected and analyzed. In these journals, the researcher analyzed the length, accuracy and complexity of T-units. In this analysis, [33] observed that although 45 percent of the students did not progress, the students wrote quicker, while enjoyed writing dialogue journals during three semesters. In addition, students' fluency in writing had increased and they became insightful and thoughtful in their writing even though their grammatical accuracy in some entries did not change.

In a research conducted by [19], the effect of dialogue journals on English learners' writing skills and language proficiency were examined. The study's focus was more on spelling, grammatical skills and students' language proficiency levels. Participants consisted of ten English language learners who for four weeks wrote their dialogue journals to their instructor. The results of this study detected students' improvement in spelling, grammar, capitalization, and punctuation, but there was no increase in language proficiency except in one of the students' writing.

Although many studies have reported the effectiveness of dialogue journal writing on writing performance, however few studies have compared this method with the conventional method in order to investigate the differences in terms of different components in writing skills.

\subsection{Participants}

\section{METHODOLOGY}

Participants in this study comprised 40 third semester TESL students at Universiti Putra Malaysia who met once a week for 90 minutes over ten-week semester during 2009-2010 academic year. Convenience sampling procedures were applied where the sample were drawn by "choosing the nearest individuals to serve as respondents" [34, p.88]. These students had received the same English writing instruction and all had gone through the same English courses. The students had taken essay writing courses and had been taught on different types of essays in writing. For the purpose of this study, the process approach was followed in which students were taught different writing processes in writing. All writing activities for both groups were conducted in the class. Based on their previous writing scores and gender, students were randomly assigned as DJW group and TBW group. The researcher personally instructed both groups in which each session was held once a weak in different days. The background information of each group is illustrated in Table 2.

Table 2. Background information of each group

\begin{tabular}{|c|c|c|c|c|}
\hline \multirow[t]{2}{*}{ Groups } & \multirow[t]{2}{*}{$\mathrm{n}$} & \multicolumn{2}{|c|}{ Gender } & \multirow{2}{*}{$\begin{array}{l}\text { Previous Writing } \\
\text { Mean score* }\end{array}$} \\
\hline & & Male & Female & \\
\hline DJW & 20 & 8 & 12 & 70 \\
\hline TBW & 20 & 6 & 14 & 64 \\
\hline Total & 40 & 14 & 26 & \\
\hline
\end{tabular}

$*$ Out of 100 


\subsection{Data collection}

In order to determine the effect of two different methods of writing on students' writing performance, a pre- and post-test writing performance was administered before and after the treatment.

In the first session, a pre-test was conducted where participants in both groups were asked to perform a writing task based on the given topics. The length and the type of writing were left to the students to decide. After going through a ten-week period, the same task with different topics was repeated as a post-test for both groups. To measure the students' writing tasks, two experienced English teachers of writing were asked to evaluate the written products by using the ESL Composition Profile [35]. The researcher and two evaluators read the profile carefully and based on their knowledge rated each writing task. In the final stage, each rater agreed upon the same score for each written product.

\subsection{Treatment for DJW and TBW groups}

The emphasis for both groups was on the process approach, namely: drafting, giving feedback, revising and editing. Therefore, the first session of the class was allocated to introducing these writing processes to the students. Additionally, since students in the DJW group were not familiar with the method of dialogue journal writing, the first session, i.e. prior to data collection, was allotted to introducing dialogue journal writing to these students. The researcher cum teacher handed the students handouts of some dialogue journals examples extracted from some articles and instructed them how to write a dialogue journal.

Students were asked to select their favorite topics and write their journals for 30 minutes in the class. The length of the writing was determined with a minimum of three sentences and the maximum was left to the students [as suggested by 36]. At the beginning of each session, the teacher handed the students some texts (extracted from articles, magazine, etc.). Students were asked to read these texts and write their own dialogue journals. In this method, they had the chance to read and get more information from the given written products and apply their understanding in their own writing tasks. At last, the teacher collected the written products at the end of each session and corrected the sentences indirectly by writing the correct forms of grammatical mistakes.

Students in TBW were asked to write their writing tasks based on the given topics and hand in their written products to the teacher. Students were notified of their grammatical mistakes by the underlines or circles and corrected form of sentences provided by teacher. They were advised to read their papers again and attempt to improve their writing. Data collection continued for ten weeks for both groups. The time and the length for writing their writing tasks were the same as DJW group.

\subsection{Instrumentation}

The instrument used in this research was a writing test which measured the writing performance quantitatively. The written entries were analyzed using the ESL Composition Profile by [35]. [37] believes that this scale is one of the best comprehensive rubrics, able to measure all important elements of writing. This scoring scale consists of five main features i.e. content (30\%), organization (20\%), vocabulary (20\%), language use $(25 \%)$, and mechanics $(5 \%)$ which each of them form the analytic writing scale. The total score was obtained by adding these points for each writing sample.

\subsection{Data Analysis}

An independent sample $t$-test was utilized to determine if there was any significant difference between DJW and TBW groups in their writing performance post-test mean scores. In order to find out whether there is any difference in their writing performance between these two groups prior to the treatment, an independent sample $t$-test was run for pre-writing scores. The result of pre-writing mean scores from independent sample $t$ test showed no significant difference between two groups in terms of overall writing performance mean scores $(t(38)=-.543, p>.05)$ and each of the categories of writing performance (Refer to Table 3$)$.

Table 3. Comparing pretest mean scores of writing performance

\begin{tabular}{llllll}
\hline & Group & Mean & SD & $t$ & $p$. \\
\hline Content & TBW & 12.44 & 1.66 & -.603 & .550 \\
Organization & DJW & 12.73 & 1.36 & & \\
& TBW & 14.49 & 2.10 & 2.005 & .052 \\
Vocabulary & DJW & 13.15 & 2.11 & & \\
& & & & & .833 \\
& TBW & 13.27 & 1.32 & .410
\end{tabular}




\begin{tabular}{lccccc}
\hline Language use & TBW & 13.95 & 1.92 & -.994 & .327 \\
& DJW & 14.61 & 2.24 & & \\
Mechanics & & & & & \\
& TBW & 11.58 & 2.63 & -.950 & .348 \\
\multirow{2}{*}{ Overall } & DJW & 12.35 & 2.50 & & \\
& & & & & \\
& TBW & 62.59 & 5.66 & -.543 & .590 \\
\hline
\end{tabular}

* rounded off to nearest number

\section{RESULTS AND DISCUSSIONS}

The obtained results from the independent sample $t$-test and the comparison made between the pre-test mean scores and post-test mean scores for each group showed that the mean scores increased due to the treatments given. The TBW pre-test mean score was 62.59 , and had increased to 68.91 during the post-test. In the DJW, an increase from a pre-test mean score of 63.59 to a post-test mean score of 70.14 was observed.

The results from the independent sample $t$-test (Table 4) showed there was no difference in the overall writing performance $[t(38)=-.735, p>.05]$ of post-test mean scores between DJW and TBW groups. For the TBW group, post-test mean scores in term of overall writing performance was 68.91 and the standard deviation score was 5.152, whereas for the DJW group, mean and standard deviation scores were 70.14 and 5.43 respectively. Comparing the mean scores for each group clearly shows that the mean score of DJW is higher than the TBW group. These findings revealed that DJW writing instruction was more effective in improving the overall writing performance. It should be noted that the mean difference between pre-test mean scores of these groups was -.995 , and for the post-test, it had increased to -1.230 .

Table 4. Comparing two groups in means scores of writing performance categories

\begin{tabular}{|c|c|c|c|c|c|}
\hline category & Group & Mean & SD & $t$ & $p$. \\
\hline \multirow[t]{2}{*}{ Content } & TBW & 13.48 & 1.44 & -5.44 & .001 \\
\hline & DJW & 16.20 & 1.704 & & \\
\hline \multirow[t]{2}{*}{ Organization } & TBW & 15.70 & 1.922 & 3.45 & .001 \\
\hline & DJW & 13.35 & 2.37 & & \\
\hline \multirow[t]{2}{*}{ Vocabulary } & TBW & 14.50 & 1.28 & -3.20 & .003 \\
\hline & DJW & 15.85 & 1.39 & & \\
\hline \multirow[t]{2}{*}{ Language use } & TBW & 16.25 & 1.91 & 3.30 & .002 \\
\hline & DJW & 14.17 & 2.07 & & \\
\hline \multirow[t]{2}{*}{ Mechanics } & TBW & 13.05 & 2.70 & -.067 & .947 \\
\hline & DJW & 13.10 & 1.99 & & \\
\hline \multirow[t]{2}{*}{ Overall } & TBW & 68.91 & 5.152 & -.735 & .467 \\
\hline & DJW & 70.14 & 5.43 & & \\
\hline
\end{tabular}

* rounded off to nearest number

The results from the Independent sample $t$-test (shown in Table 4) which compared post-test mean scores of each categories of writing performance between TBW and DJW groups showed the differences in content $(p<.05)$, organization $(p<.05)$, vocabulary $(p<.05)$ and language use $(p<.05)$, while there was no significant difference $(p>.05)$ between TBW and DJW in terms of mechanics.

Comparison between the mean scores for each categories of writing performance between TBW and DJW, revealed that TBW outperformed their counterpart in terms of organization $(M=15.70)$ and language use $(M=16.25)$. However, DJW outperformed their rival in terms of content $(M=16.20)$ and vocabulary $(M=15.85)$.

The link between language use and organization to TBW can be explained by the feedback and comments provided by the teachers. Teachers gave comments and feedback based on grammatical mistakes and organization of the written products. The researcher corrected the grammatical mistakes directly by underlining or circling the mistaken grammatical structure. Consequently, this noticing made students focus more on the language use and organization of their writing tasks.

In contrast, DJW students performed better in content and vocabulary. It shows that receiving indirect comments and feedback on the grammatical mistakes was not effective in terms of language use and organization when compared to the TBW group. It can be observed that DJW students' focus was more on content and suitability of vocabularies as to make their writing outcome more understandable. Students were 
more likely to have expressed their ideas in their comfort zone where they feel safe when corresponding with their teachers. This trust gained the students comfort in expressing their thoughts and ideas [38], without worrying about the grammatical mistakes and consequently have resulted in improving their content and vocabulary.

The reason for the improvement in writing performance in terms of content and vocabulary through the use of dialogue journal writing has also been reported by other researchers. [39] believes that exchanging dialogues provides time for learners to reflect and frame their thoughts more accurately and even check their conflicting ideas before passing them to their partners or teacher. He believes that this kind of careful and planned formation of ideas, rarely occurs in the immediate exchanges of conversation. [40] also believes that journaling is a way to integrate raw material of experience with the existing knowledge and to develop a new meaning.

With regard to mechanics, comparison between pre- and post-test mean scores shows increase in the mean scores for both groups. However, no statistically difference was observed in the post-test mean scores between groups. One of the possible explanations of this result could be related to the fact that all students had gone through the same instruction provided by the instructor and both groups were aware of the correct mechanics to be applied in their writing.

\section{CONCLUSION}

Results of the mean scores obtained in the overall writing performance and its components showed there was an increase in the pretest to posttest conducted. This indicates that the students' writing skills have improved through both writing methods, i.e. DJW and TBW. Comparison between the post-test mean scores in terms of overall writing performance revealed that there was no significant difference between these two groups, however there were significant differences in terms of content, organization, language use and vocabulary between these two groups. In terms of mechanics, no statistical difference was observed.

Findings of this study suggest that writing teachers can utilize both writing strategies in their classes depending on the students' writing needs. The findings of this study support some researchers' point of view in the effective use of dialogue journal writing in improving writing skills $[19,5,7,33 ; 10 ; 4 ; 3]$.

Teacher-students or peers corresponding through dialogue journals offer the chance for writing back and forth to the teacher, improving both writing and reading simultaneously. By providing the opportunities to have correspondence out of the class, more time can be allocated where students will feel more comfortable and relaxed as they write.

This study proposed a method in using dialogue journal writing in the class where students have the chance to convey their information, skills and feelings, while unconsciously improving their writing skills. As [7] mentioned, "writing is a tool of thought and communication"(p.3), it is not a combination of unrelated and pre-organized pieces of sentences, but a cognitive task consisting of higher levels of thinking skills which can be improved by using dialogue journal writing.

It should be mentioned that the art of dialogue journal writing is beneficial for prospective teachers particularly in the pre-service teacher programs as they acquire the methods in teaching but without any chance to apply their skills and practice them among themselves. The role of transferring students' acquired skills to others should be considered in teacher education courses. In this case, dialogue journal writing can be viewed as a method for reflecting the knowledge as students through their education have to practice, improve and use their reflection skills [41]. In short, dialogue journal writing has been regarded as "a bridge to help prospective teachers narrow the gap between imagined views of teaching held by students and the realities of teaching experienced by practicing teachers" $[20, \mathrm{p} .3]$.

\section{References}

[1] A. Cumming, and A. Riazi, Building models of adult second-language writing instruction. Learning and Instruction. 10, 2000, 5571.

[2] D.R. Ferris and J. S. Hedgcock, Teaching ESL Composition: Purpose, Process, and Practice (Mahwah, NJ: Lawrence Erlbaum.2 $2^{\text {nd }}$ ed, 2005).

[3] J.K. Peyton, Students and teachers writing together: Perspectives on journal writing (Alexandra, VA: Teachers of English to Speakers of Other Languages, Inc. 1990).

[4] J.K. Peyton and L. Reed, Dialogue journal writing with nonnative English speakers: A handbook for teachers (Alexandria, VA: TESOL, EDRS No. ED 365 139, 1990).

[5] M. Song, The effect of dialogue journal writing on writing quality, reading comprehension, and writing apprehension of EFL college students, 1997, (ERIC 410766).

[6] L. Reid, Exploring the ways that dialogue journaling affects how and why students write: An action research project. Teaching and Change. 5(1): 1997, 50-57

[7] V.L. Holmes and M.R. Moulton, Dialogue journals as an ESL learning strategy. Journal of Adolescent and Adult Literacy. 40(8), 1997, 616-621.

[8] J. Kreeft, Dialogue writing: Bridge from talk to essay writing. Language Art, 61(2), 1984, 141-150. 
[9] Y.M. Wang, E-mail dialogue journaling in an ESL reading and writing classroom. International JI .of Educational Telecommunications . 4 (2/3), 1998, 263-287.

[10] J.K., Peyton, J. Staton, G. Richardson and, W. Wolfram, The influence of writing task on ESL students' written production. Research in the teaching of English. 24 (2), 1990, 142-171.

[11] V.L. Holmes and M.R. Moulton, A contrarian view of dialogue journals: The case of a reluctant participant. Journal of Second Language Writing, 4, 1995, 223-251.

[12] H. Nassaji and A. Cumming, What's in a ZPD? A case study of a young ESL student and teacher interacting through dialogue journals. Language Teaching Research, 4(2), 2000, 95-121.

[13] L. Vygotsky, Mind in society: The development of higher psychological processes (Cambridge: Harvard University Press, 1978).

[14] B. Ulusoğlu-Darn, ARP: Journal Writing: A Study of Change, 2008. Available at: http://www.stevedarn.com/?Writings::ARP\%3A_Journal_Writing\%3A_A_Study_of_Change.

[15] R. Garlikov, Significant $\quad$ Differences $\quad$ Between $\quad$ Writing Why Talking Seems Easier, 2000. Available at: http://www.garlikov.com/talkwrite.htm.

[16] R. Weissberg, Acquiring English syntax through journal writing. College ESL, 8: 1998, 1-22.

[17] R. Spack and C. Sadow. Student-teacher working Journals in ESL freshman composition. TESOL Quarterly, 17(4), 1983, 573-579.

[18] R. S. Baskin, Student feedback on dialogue journals. National Institute of Education, Eric Resources Information Center (ERIC Document Reproduction Service No.ED375627, 1994.

[19] L., K. Koch, The effect of dialogue journals on English language learners' syntax, spelling, and language proficiency. Master diss., Kremen School of Education and Human Development, California State University, Fresno, 2005.

[20] I. Lee, Using Dialogue Journals as a Multi-Purpose Tool for Preservice Teacher Preparation: How Effective Is It? Teacher Education Quarterly. Summer, 2004, 73-97.

[21] G. K. Suraishkumar, (2003). Improving Coherence in Technical Writing. Chemical Engineering Education. 38, 2003, 116-120.

[22] A. Peretz, Teaching Scientific/Academic Writing in the Digital Age. The Electronic Journal of e-Learning, 3(1), 2005, 55-66. Available online at: www.ejel.org.

[23] k. Kelly, Computer-Assisted Writing Instruction: A Marriage of Effective Instruction and Technology. A Review of Literature. Computer-Assisted Writing Instruction, 2002. Available at: http:// chiron. valdosta. edu/ are/ vol1 no $2 / 1$ i trev/KarenKelly.pdf

[24] J. Myles, Second Language Writing and Research: The Writing Process and Error Analysis in Student Texts. TESL-EJ, 6 (2), 2002.

[25] H. Hollingsworth and S. Eastman, Teaching writing in every class: a guide for grades 6-12 (Boston: Allyn and Bacon Inc., 1988).

[26] C. Tribble, Writing (Oxford: Oxford University Press, 1996).

[27] L. Bryan. Writing Changes and Related Influences as Revealed Through Dialogue Journal Analyses, doctoral diss, University of Louisiana at Lafayette, 2004.

[28] W. Huitt, Motivation to learn: An overview. Educational Psychology Interactive (Valdosta, GA: Valdosta State University, 2001).

[29] P. Oudeyer, and F. Kaplan, What is intrinsic motivation? A typology of computational approaches, 2007. From: Neurorobot.1:6.doi:10.3389/neu ro. 12/006.2007.

[30] R. M. Ryan, and E. L. Deci, Intrinsic and extrinsic motivations: Classic definitions and new directions. Contemporary Educational Psychology, 25, 2000, 54-67.

[31] R. Bruning C. Horn. Developing motivation to write. Educational Psychologist, 35 (1): 2000, 25-37.

[32] S. Hudelson, Children's Writing in ESL, 1988. Available at: http://www.ldonline.org/article/287.

[33] C. P. Casanave, Language development in students' journals. Journal of Second Language Writing. 3 (3), 1994, 179-201.

[34] L. Cohen and L. manion, Research methods in education (London: Routledge, 1994).

[35] H.L. Jacobs, S.A. Zinkgraf, D.R. Wormuth, V.F. Hartfiel, and J. Hughey. Testing ESL composition: A practical approach (Rowley, MA: Newbury House, 1981).

[36] J. K. Peyton, Dialogue Journals: Interactive Writing to Develop Language and Literacy, 2000. Available at: http://www.cal.org /caela/esl_resources /digests /Dialogue_Journals.html.

[37] Lam, F. S. \& Pennington, M. C. 1993. The computer vs. the pen: A comparative study of word processing in a Hong Kong secondary classroom. Perspectives 5(2), 63-75.

[38] M. A. Garmon, Using dialogue journals to promote student growth in a multicultural education course. Remedial and Special Education, 19(1), 1998, 32-45.

[39] J. Killion, Journaling. National Staff Development Council, Journal of Staff Development, Summer, $20(3), 1999,36-37$.

[40] S. Kerka, Journal Writing as an adult learning tool, ERIC 470782.

[41] S.E. Walker, Journal writing as a teaching technique to promote reflection. Journal of athletic training, 41(2), 2006, 216-221. 